\title{
Intracranial Hypotension with Severe Neurological Symptoms Resolved by Epidural Blood Patch
}

\author{
Philip W.H. Peng
}

\begin{abstract}
Background: A patient with a constellation of severe neurological symptoms caused by spontaneous intracranial hypotension, which was successfully managed by epidural blood patch, was described. Case history: A 50-year-old woman presented to the neurological service with a two-month history of orthostatic headache. Associated clinical features included sensorineural deafness, ataxia and short-term memory loss. Magnetic resonance imaging showed downward displacement of brain structures, bilateral subdural collections and the postgadolinium images demonstrated diffuse dural enhancement suggestive of the diagnosis of spontaneous intracranial hypotension. Results: Following a lumbar epidural blood patch, all symptoms improved significantly and her headache resolved. Conclusion: The principal presentation of spontaneous intracranial hypotension is orthostatic headache. The patient described presented a combination of various neurological symptoms, ataxia, memory loss and deafness, which all responded well to epidural blood patch.
\end{abstract}

RÉSUMÉ: Hypotension intracrânienne associée à des symptômes neurologiques sévères traitée parcolmatage sanguin épidural. Introduction: Nous décrivons le cas d'une patiente qui présentait une constellation de symptômes neurologiques sévères causés par une hypotension intracrânienne spontanée traitée avec succès par colmatage sanguin épidural. Cas clinique: Il s'agit d'une femme âgée de 50 ans qui a consulté en neurologie parce qu'elle présentait une histoire de céphalées orthostatiques depuis deux mois, associées à une surdité neurosensorielle, à une ataxie et à une perte de mémoire à court terme. L'imagerie par résonance magnétique a montré un déplacement vers le bas des structures cérébrales, des collections liquidiennes sous-durales bilatérales et des images post-gadolinium montrant un rehaussement dural diffus suggestif d'un diagnostic d'hypotension intracrânienne spontanée. Résultats: Tous les symptômes ont régressé suite au traitement par colmatage sanguin épidural lombaire et les céphalées ont disparu. Conclusion: Le mode de présentation principal de l'hypotension intracrânienne spontanée est la céphalée orthostatique. Notre patiente présentait des symptômes neurologiques variés, soit de l'ataxie, une perte de mémoire et une surdité, qui ont régressé suite à un colmatage sanguin épidural.

Can. J. Neurol. Sci. 2004; 31: 569-571

Spontaneous intracranial hypotension $(\mathrm{SIH})$ was first reported as a condition marked by low or even negative cerebrospinal fluid (CSF) pressure. ${ }^{1}$ Clinically, it is characterized by orthostatic headache and may respond well to epidural blood patch. ${ }^{2}$ Other neurological presentations of SIH have been diplopia, ${ }^{3}$ memory loss, ${ }^{4}$ hearing deficit, ${ }^{3,5}$ parkinsonism, ${ }^{6}$ ataxia, ${ }^{6}$ obtundation ${ }^{7}$ and even coma. ${ }^{8}$ In the present case report, a case in which a patient developed a constellation of severe neurological symptoms thought to be related to orthostatic hypotension that improved significantly after epidural blood patch was described.

\section{Case history}

A 50-year-old woman was admitted to the neurology service because of a history of posture-related headache. Two months prior to the admission, she sustained a trivial fall down stairs at work. She then noticed severe headache the following day. On lying down, her headache disappeared, to the extent that she had to lie on the floor under the table at work to obtain relief. She also noticed short-term memory loss, hearing impairment and unsteady gait. She also had an episode of nausea and vomiting with hematemesis, which brought her to the emergency room. There she was investigated with a CT scan, which showed bilateral small subdural hematomas. She was referred to a neurologist

From the Department of Anesthesia, Toronto Western Hospital, University Health Network, University of Toronto, Toronto, Ontario Canada.

ReCEIVED OCtOBER 14, 2003. ACCEPTEDin FinAlFORM JANUARY 28, 2004. Reprint requests to: Philip Peng, Department of Anesthesia, EC 2-046, Toronto Western Hospital, 399 Bathurst Street, Toronto, Ontario M5T2S8 Canada. 
A

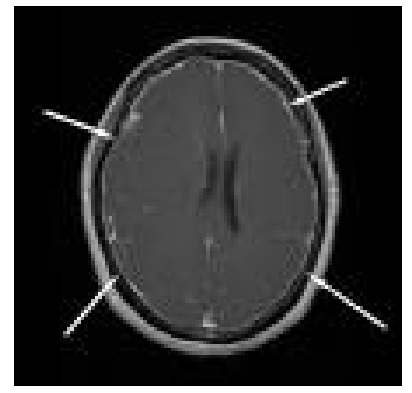

Figure A: Axial T1-weighted image post-gadolinium showed diffuse enhancement of dura (outlined by arrows).

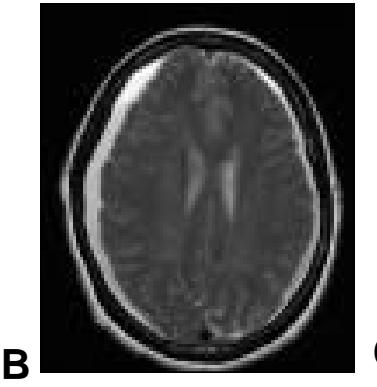

Figure B: Axial T2weighted image showed bilateral subdural collec . tions.

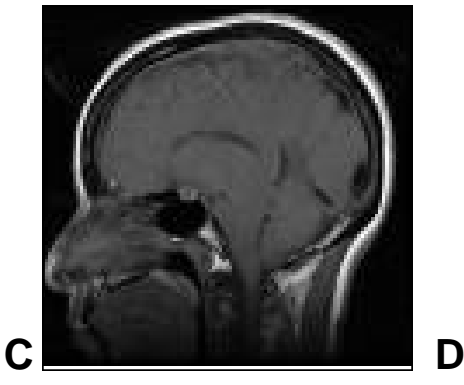

Figure C: Sagittal T1weighted image showed downward displacement of brainstem, obliteration of the suprasellar cistern and flattening of the pons against the clivus.

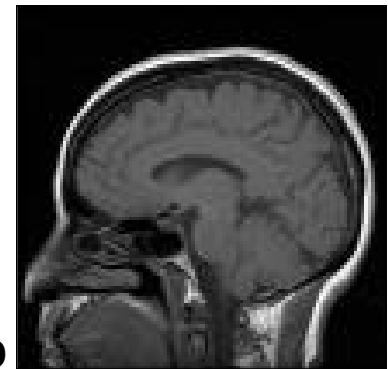

Figure D: Sagittal T1weighted image of the same patient 10 months later showed resolution of the abnormalities revealed in Figure $C$. for further investigation. She had past history of hypertension on diuretics, otherwise she enjoyed good health.

At the time of admission to the neurology ward, she scored 26 out of 30 in Mini-Mental State Examination ${ }^{9}$ with 0 point for all three questions of short-term memory. Cranial nerve examination was unremarkable except for a decrease in hearing which was worse on the right side. She had ataxia of upper extremities and lower extremities on the finger-nose test and heel shin test respectively. Gait was completely ataxic and she was not able to perform tandem walking independently. Muscle power examination showed mild weakness in both deltoids with motor grade 4 over 5 bilaterally. Both upper and lower limbs reflexes were normal except extensor plantar responses. Ankle clonus was absent.

Her audiogram confirmed bilateral asymmetric sensorineural hearing loss that was worse on the right side. Magnetic resonance imaging (MRI) showed downward displacement of brain structures, bilateral subdural collections and the post gadolinium images demonstrated diffuse dural enhancement (Figure A-D).

She was referred to the department of anesthesiology for possible epidural blood patch, which was performed during the hospital stay. It was performed in the left lateral position and the epidural needle was inserted at lumbar 3/4 interspace. The epidural space was located with loss-of-air resistance technique. Twenty-five $\mathrm{ml}$ of blood was taken from the antecubital vein of the same patient and administered into the epidural space. The patient's headache worsened transiently at the end of the injection. Within 24 hours, she started to have some symptomatic improvement in headache and was virtually headache-free after two days. On the day of discharge, four days after the epidural blood patch, she was able to tandem walk independently with no ataxia. She still has slight difficulty in short-term memory but she was able to remember all three words in the last Mini-Mental State Examination.

She was seen again two months after discharge, by which time she had recovered further function. She had no motor deficit including the deltoids and could manage tandem walking. The plantar reflexes were normal again. Although her hearing did not completely recover, her deafness did not impact significantly on her daily living or her job in an accounting department of a bank.

\section{Discussion}

Spontaneous intracranial hypotension is an uncommon cause of headache and is related to low CSF pressure and volume. Current evidence has implicated CSF leakage as the major cause of low CSF volume. ${ }^{10}$ The exact cause of the leakage is unknown. It is believed to be contributed by trivial traumatic injury ${ }^{11}$ and weakness of the meningeal sac, such as rupture of congenital, perineural (Tarlov) cysts or diverticuli of spinal nerve sleeves. ${ }^{12}$ The classical symptom is orthostatic headache. However, atypical presentation such as nonpositional headache and chronic daily headache can occur. ${ }^{10,13} \mathrm{~A}$ variety of associated neurological symptoms have been reported and this is likely to be related to the downward displacement of the cerebrum causing compression or traction of various neural structures. In the past decade, MRI has revolutionized our understanding and recognition of this syndrome. Typically, MRI shows diffuse pachymeningeal enhancement, sagging of the brain (descent of the cerebellar tonsils sometimes mimics Chiari I malformation) and subdural fluid collections. ${ }^{10}$ Radioisotope cisternography may be useful to localize the site of leakage. The common sites are in the cervicothoracic junction and thoracic area ${ }^{10}$ although the lumbar region was reported as the most common area of leakage in a recent large series. ${ }^{2}$

Most cases of SIH resolved spontaneously. Medical management, such as administration of caffeine, glucocorticoid and theophylline, are of limited benefit. Epidural blood patch is an effective treatment for headache for patients not responding to simple medical measures. ${ }^{4,10}$ Neurological symptoms other than headache, such as parkinsonism, and ataxia, ${ }^{6}$ tinnitus and deafness, ${ }^{5}$ may also be responsive to blood patch. In patients with hearing impairment, there are two possible causes. One is sensorineural hearing loss caused by distortion of the eighth cranial nerve from traction or pressure. ${ }^{6}$ The other is labyrinthine hydrops. In some individuals with patent cochlear aqueduct, loss of CSF may result in compensatory expansion of the endolymph compartment. A previous case, in which hearing loss was 
reversed by a blood patch, was caused by labyrinthine hydrops. ${ }^{5}$ However, our reported patient suffered from sensorineural hearing loss as documented by audiogram, which may account for the slow and incomplete recovery of hearing at five month follow-up. Frontotemporal dementia caused by SIH has also been reported. In that case report, the dementia was managed and reversed by a four-month course of oral steroid. ${ }^{4}$ The patient described in our report is unique in that she presented with a constellation of severe neurological symptoms, which improved significantly with epidural blood patch. It is important for neurologists to recognize that epidural blood patch should be considered as one of the treatment modalities in spontaneous intracranial hypotension, even in the presence of multiple severe neurological symptoms.

In summary, a patient with spontaneous intracranial hypotension presenting with a constellation of various severe neurological symptoms, which responded and improved significantly after receiving epidural blood patch, was reported.

\section{REFERENCES}

1. Khurana RK. Intracranial hypotension. Semin Neurol 1996; 16:5-9.

2. Chung SJ, Kim JS, Lee MC. Syndrome of cerebral spinal fluid hypovolemia. Clinical and imaging features and outcome. Neurology 2000; 55:1321-1327.

3. Blank SC, Shakir RA, Bindoff LA, Bradey N. Spontaneous intracranial hypotension: clinical and magnetic resonance imaging characteristics. Clin Neurol Neurosurg 1997; 99:199204.
4. Hong M, Shah GV, Adams KM, Turner RS, Foster NL. Spontaneous intracranial hypotension causing reversible frontotemporal dementia. Neurology 2002; 58:1285-1287.

5. Portier F, de Minteguiaga C, Racy E, Huy PTB, Herman P. Spontaneous intracranial hypotension: a rare cause of labyrinthine hydrops. Ann Otol Rhinol Laryngol 2002; 111:817820.

6. Pakiam AS, Lee C, Lang A. Intracranial hypotension with parkinsonism, ataxia and bulbar weakness. Arch Neurol 1999; 56:869-872.

7. Binder DK, Dillon WP, Fishman RA, Schmidt MH. Intrathecal saline infusion in the treatment of obtundation associated with spontaneous intracranial hypotension: technical case report. Neurosurgery 2002; 51:830-837.

8. Evans RW, Mokri B. Spontaneous intracranial hypotension resulting in coma. Headache 2002; 42:159-160.

9. Folstein MF, Folstein SE, McHugh PR. "Mini Mental State": a practical method for grading the cognitive state of patients for the clinician. J Psychiatr Res 1975; 12:189-198.

10. Mokri B. Spontaneous cerebrospinal fluid leaks: from intracranial hypotension to cerebrospinal fluid hypovolemia-evolution of a concept. Mayo Clin Proc 1999; 74:1113-1123.

11. Diaz JH. Epidemiology and outcome of postural headache management in spontaneous intracranial hypotension. Reg Anesth Pain Med 2001; 26:582-587.

12. Vishteh AG, Schievink WI, Baskin JJ, Sonntag VKH. Cervical bone spur presenting with spontaneous intracranial hypotension. Case report. J Neurosurg 1998; 89:483-484.

13. Schievink WI, Smith KA. Nonpositional headache caused by spontaneous intracranial hypotension. Neurology 998; 51:17681769. 